\title{
CRISE: EVENTO IMINENTE COM GRANDE POTENCIAL TRANSFORMADOR
}

ANA KARIN NUNES

UNIVERSIDADE FEDERAL DO RIO GRANDE DO SUL PORTO ALEGRE, RIO GRANDE DO SUL, BRASIL ANA.KARIN@UFRGS.BR 


\section{CRISE: EVENTO IMINENTE COM GRANDE POTENCIAL TRANSFOR- MADOR}

Resumo: $O$ artigo trata da crise como um evento iminente, de grande impacto em contextos organizacionais e de figuras públicas e celebridades. Tem como objetivos propor o entendimento de crise como uma das etapas do processo de cooperação-conflito e contribuir para o entendimento de crises como eventos inevitáveis, os quais possuem grande capacidade de gerar aprendizados para todos os atores envolvidos.

Palavras-chave: crise; aprendizado organizacional; relações públicas.

\section{CRISIS: EVENTO INMINENTE CON GRAN POTENCIAL TRANSFORMA- DOR}

Resumen: El artículo aborda la crisis como un evento inminente, de gran impacto en contextos organizacionales y figuras públicas y celebridades. Tiene como objetivos proponer la comprensión de la crisis como una de las etapas del proceso de cooperación-conflicto y contribuir a la comprensión de las crisis como eventos inevitables, que tienen una gran capacidad de generar aprendizaje para todos los actores involucrados.

Palabras Clave: crisis; aprendizaje organizacional; relaciones públicas.

\section{CRISIS: IMMINENT EVENT WITH GREAT TRANSFORMATIVE POTEN-} TIAL

Abstract: This article is about crisis as an imminent event, of great impact in contexts of organizations, public figures and celebrities. Its objectives are to propose the understanding of crisis as one of the stages of the process of cooperation-conflict and contribute to the understanding of crisis as inevitable events, which have great ability to generate learning for all actors involved in it.

Keywords: crisis; organizational learning; public relations.

\section{INTRODUÇÃO}

A gestão de crise tem sido assunto recorrente desde a década de 1990, quando os primeiros estudos sobre cultura organizacional começaram a ser desenvolvidos no Brasil. Nos últimos quinze anos, com a democratização do acesso à Internet e o advento das redes sociais digitais, o tema ganhou novas nuances. A agilidade na geração e disseminação de conteúdos sobre pessoas e organizações faz crescer a ideia de que, atualmente, vive-se num contexto com um número maior de crises. Contudo, há que se destacar que crises sempre existiram e, por melhores que sejam as intenções dos profis- 
sionais que delas se ocupam, são parte inevitável numa sociedade alimentada por relações de múltiplos e conflitantes interesses. Pessoas e organizações vivem em iminente situação de crise e, sabedoras disso, podem agir antecipadamente, de forma a atravessá-las gerando o mínimo possível de impactos à sua manutenção em sociedade.

Dito isso, este artigo tem como primeiro objetivo propor o entendimento de crise como uma das etapas do processo de cooperação-conflito no sistema organização-públicos, a qual precisa ser diferenciada de fatos, insatisfações ou boatos isolados. A crise está sempre em iminência na medida em que uma organização se relaciona com o meio no qual está inserida. Porém, suas características e poder de impedimento são bastante distintas de problemas aos quais todo e qualquer sistema organizacional está sujeito na relação que estabelece com o seu meio. Compreender as sutis diferenças entre essas etapas presentes na relação organização-públicos pode ser determinante para o planejamento de ações de comunicação, tanto preventivas quanto corretivas, visando a preservação de bens intangíveis como a reputação organizacional.

Na perspectiva da função organizacional política de relações públicas, o conceito de crise está relacionado à perda de controle, ao desequilíbrio e à ruptura nas relações. Em boa parte das vezes, a crise é antecedida por estágios de insatisfação, boatos, rumores, os quais precisam ser tratados com estratégias que visem o reequilíbrio das relações, de forma que as situações não se agravem.

Independente da construção e manutenção de planos de prevenção e gerenciamento, crises são eventos inevitáveis, com os quais organizações e figuras públicas precisam aprender a conviver e construir históricos de aprendizado. Ou seja, os profissionais de relações públicas precisam compreender que não é sua função evitar crises, mas construir aprendizados significativos com elas, os quais gerem relações mais conscientes e maduras. Daí emerge o segundo objetivo deste artigo, qual seja contribuir para o entendimento de crises como eventos inevitáveis, os quais possuem, de um lado, grande poder de impacto negativo sobre a imagem e reputação e, de outro lado, grande capacidade de gerar aprendizados para todos os atores envolvidos.

Para atingir os objetivos propostos utilizou-se de revisão bibliográfica e da ilustração de casos recentes de crises envolvendo organizações, figuras públicas e celebridades. Ao final, propõe-se a estruturação de planos de 
prevenção e gestão de crise que envolvam a construção intencional de um conjunto de aprendizados organizacionais, os quais podem contribuir para um sistema organização-públicos mais eficiente.

\section{CRISE NA PERSPECTIVA DA FUNÇÃo ORGANIZACIONAL POLÍTICA DE RELAÇÕES PÚBLICAS}

Relações públicas, segundo a teoria da função organizacional política proposta por Simões (1995), é uma ciência que tem por objetivo a cooperação mútua entre as partes do sistema organização-públicos. Ocupa-se, por meio de filosofia, política e normas, das relações entre a organização e os seus públicos, em benefício de interesses comuns. O objeto formal de responsabilidade do profissional é a bipolaridade conflito/cooperação. Nessa perspectiva, é salutar compreender que na sua relação com os diversos públicos de interesse, uma organização está em permanente estágio de embate/ harmonia. Esse equilíbrio perseguido pela atividade de relações públicas se traduz na atuação planejada e na efetivação de estratégias pautadas na ética, na transparência, no diálogo e na redução da incerteza nas relações. Ou seja, por meio de políticas, diretrizes e ações de comunicação e relacionamento.

Visando esclarecer as diferentes fases implicadas entre esses dois estágios, cooperação e conflito, Simões (1995) propõe a categorização da relação organização-públicos em dez níveis: 1) interesses satisfeitos: ambas as partes da relação, organização-público, estão satisfeitas com as decisões e não se registram contrariedades; 2) insatisfação: fatores de diversas naturezas, seja no âmbito interno ou externo, geram desconfortos na relação, alterando percepção e a disponibilidade de cooperação; 3) fofocas, boatos, rumores e charges: falta de liderança e transparência perante os fatos, entre outros aspectos, abrem espaço para a geração de informações equivocadas sobre a estrutura organizacional; 4) coligações: boatos e rumores geram suspeitas e ameaças, fazendo com que as pessoas se reúnam em torno de líderes de opinião, os quais nem sempre detém a verdade sobre os fatos; 5) pressão junto ao poder organizacional: com relativa organização, o público reúne forças para pressionar e influenciar decisões organizacionais; 6) conflito: gera-se um impasse no processo decisório, mesmo frente a tentativas de resolução do problema; 7) negociação: começam a haver concessões entre ambas as partes, na tentativa de que o impasse não se agrave; 8) crise: perda do controle da situação, estado de desequilíbrio que distancia ainda mais as 
partes envolvidas na relação; 9) arbitragem: uma terceira parte, em geral o Estado, intervém na situação, tomando decisões, em geral, contrárias aos interesses de ambas as partes; e 10) convulsão social: o antagonismo extremo gera a violência, exemplificada através de sabotagens, motins e agressão pessoal e ao patrimônio físico.

Com relação aos dez níveis dos estágios cooperação/conflito, cumpre destacar que não ocorrem de forma linear ou sequencial. A relação entre a organização e um determinado público pode, por exemplo, partir, imediatamente, de um estágio de satisfação para conflito. Ainda, o que determinará a intensificação ou não de cada um dos níveis é a capacidade de diálogo entre as partes. Nesse tocante, a gestão de estratégias de comunicação condizentes com cada situação, alinhadas com o propósito organizacional, contribui sobremaneira para o acirramento ou harmonização de um dado cenário. Não são incomuns os casos, por exemplo, de marcas que ao responderem de forma não planejada a um comentário de insatisfação com um produto numa mídia digital acabam provocando ainda mais boatos, rumores, ou mesmo propiciando a coligação de diferentes clientes e líderes de opinião em oposição à organização.

Crise, portanto, é um dos níveis possíveis dos estágios cooperação/ conflito no sistema organização-públicos. Crise diz respeito à instabilidade e perda de controle da relação entre a organização e um determinado público. Está associada, em sistemas capitalistas, especialmente, à perda significativa de poder econômico e/ou de audiência. Situações de crise, em geral, são antecedidas por insatisfações e/ou por contextos de riscos envolvendo pessoas, processos e estruturas mal gerenciados ou negligenciados. Expressam uma situação que ameaça a integridade de uma pessoa ou organização, trazendo danos à reputação. Outra característica bastante particular da crise é que ela ganha repercussão na mídia, entra na agenda de veículos de comunicação.

No âmbito organizacional, Shyniashiki, Fischer e Shyniashiki (2007) argumentam que as crises podem ameaçar a sobrevivência de um sistema, exigindo resposta rápida. Ninguém está imune a uma situação conflituosa. O que garantirá a continuidade ou a descontinuidade de um negócio num cenário de crise é a capacidade de ações planejadas, coerentes e efetivas. Forni (2017) destaca que uma crise sempre representa um passivo de imagem, um arranhão na reputação, seja de empresas, governos ou pessoas. Mais uma justificativa para que as estruturas disponíveis para gerenciar crises 
tenham uma visão profissional de longo prazo, considerando a estratégia organizacional e sua repercussão nos diversos públicos de interesse.

Já no contexto de pessoa física, envolvendo casos de figuras públicas e celebridades, ainda são raras as iniciativas estratégicas a longo prazo desenvolvidas no Brasil. Por outro lado, nos Estados Unidos, há uma vasta rede de serviços e profissionais especializados em gerenciar não apenas os meios de comunicação usados por figuras públicas e celebridades, mas também o relacionamento que estabelecem com o seu meio, discursos, posicionamentos e atitudes. Casos como o de Harvey Weinstein (GRESSLER, 2018), um dos maiores produtores cinematográficos de Hollywood, aumentaram a visibilidade de crises envolvendo pessoas que gozam de grande prestígio da mídia, mas que ferem direitos humanos fundamentais. Cohen (2019) alerta que casos graves como este tem levado publicitários e profissionais de relações públicas americanos a se questionarem se devem ou não continuar gerenciando carreiras ou mesmo aceitar defender celebridades e figuras públicas que tenham se envolvido em escândalos de ordem comportamental, que ferem os preceitos da moral. Diferente dos advogados, por exemplo, que partem da ideia de que todo ser humano merece direito de defesa, agências de relações púbicas vivem da sua reputação e, portanto, também buscam evitar crises. De toda forma, cabe ressaltar que figuras públicas e celebridades, em analogia a uma organização, também formam sistemas de relações complexos, vivem em permanente estágio de cooperação/conflito. Crise, nesse tocante, diz respeito a tudo que pode inviabilizar a imagem de uma figura pública ou celebridade, seja perante seu público mais fiel ou frente à sociedade em geral. Essa inviabilização passa por perdas econômicas ligadas a contratos de publicidade, contratos de trabalho e processos judiciais, bem como por perdas de audiência.

Diferentemente dos eventos conflituosos do cotidiano, uma crise reflete um acontecimento, em geral surpreendente, que pode interferir negativamente na consecução dos objetivos e da missão de uma organização ou na reputação de uma pessoa física. Daí que se argumenta que requer atuação rápida, por meio de planos de gestão de crise, os quais visam orientar a tomada de decisão e dirimir os seus efeitos, sair o mais rápido possível do agendamento da mídia. Esses planos devem ser elaborados com antecedência, buscando prever situações possíveis de crise, embora nem sempre serão tão efetivos nesse tocante. Planos de gestão de crise acabam servindo muito mais como um guia que estabelece políticas e estratégias 
gerais para atuação em situações de conflito do que como uma "bola de cristal" onde todas as respostas estarão disponíveis.

Dado o cenário apresentado até aqui, parte-se, na sequência, para a discussão da crise como um evento iminente.

\section{CRISES SÃO IMINENTES}

O Project Management Institute (PMI), principal organização internacional na área de gestão de projetos, lançou recentemente uma iniciativa denominada Brightline. Seu propósito é construir, em conjunto com outras organizações globais, dados pertinentes que agreguem valor à estratégia e ao direcionamento de negócios. Um dos relatórios produzidos tem como tema central as crises, como operam e como mudam a forma como as organizações trabalham e se relacionam com o seu meio. Ele se baseia em uma pesquisa realizada em 2018, com 1.258 executivos que já haviam experienciado situações de crise. Foram entrevistadas pessoas da América do Norte, Europa, Oriente Médio, Ásia, Austrália e Ilhas do Pacífico, sendo 69\% do setor privado, $26 \%$ do setor governamental e $5 \%$ de entidades não governamentais.

Segundo o PMI Brightline (2018, p.08, tradução nossa), crise é “um evento crítico ou ponto de decisão o qual, se não for tratado de maneira apropriada e oportuna (ou simplesmente nem tratado), poderá se transformar em desastre ou catástrofe". Do total de entrevistados pela pesquisa, $68 \%$ consideram inevitável ter que lidar com situações de crise no futuro. As crises são iminentes, podem acontecer a qualquer momento e se originar em fatores diversos.

Um exemplo recente de crise originada em um cenário aparentemente pacífico é o caso do movimento Escoteiros do Brasil, organização não governamental de atuação internacional, com foco educacional. Em agosto de 2019 os principais telejornais do Estado do Rio Grande do Sul, Brasil, divulgaram depoimentos de integrantes do grupo que haviam sido vítimas de abuso sexual por um voluntário, desligado do movimento desde o ano de 2016. $\mathrm{Na}$ época dos abusos, as 18 vítimas denunciantes eram menores de idade e o voluntário exercia papel de destaque junto à entidade. Apesar de o caso correr em segredo de justiça e o Escoteiros do Brasil não ter sido citado no processo judicial, movido diretamente pelas vítimas contra o abusador, a entidade precisou se posicionar rapidamente sobre o assunto. Isso porque a mídia citava diretamente a organização, a relação entre integrantes e volun- 
tários durante o trabalho desenvolvido. A transparência e postura proativa adotada pelo movimento Escoteiros do Brasil foi fundamental para que a crise não se aprofundasse e saísse rapidamente do agendamento da mídia.

Um relatório de pesquisa produzido no Brasil, pela Deloitte (2015), construído a partir da escuta a 95 gestores de organizações que atuam no país, apontou que entre as crises mais enfrentadas nesse contexto estão as relacionadas a aspectos econômicos, desastres naturais e de produto. Crises relacionadas à segurança da informação também tiveram destaque. A pesquisa também identificou que as organizações brasileiras se voltam muito mais ao fortalecimento de estruturas internas de gestão de riscos do que de gestão de crise. Embora reconheçam a pertinência do tema e os efeitos da crise na imagem e reputação organizacional, são raras as estruturas que planejam a gestão de crise de forma integrada e alinhada à estratégia do negócio.

Quando analisadas as crises envolvendo figuras públicas e celebridades brasileiras, esse pouco investimento em estruturas capacitadas para uma gestão eficaz fica ainda mais evidente. O caso do jogador de futebol masculino, Neymar é um bom exemplo. O atleta configura entre os cinco maiores salários do esporte mundial e já esteve envolvido em várias situações de conflito. A mais recente delas, repercutida nos principais veículos da mídia internacional no primeiro semestre de 2019, tratava de um suposto caso de abuso sexual do jogador contra uma modelo brasileira. Segundo dados da Decode Research and Analytics (2019), no auge da crise, entre 25 de maio a 02 de junho, o alcance digital do caso foi de 92 milhões de pessoas. As menções relacionadas ao jogador nas redes sociais digitais aumentaram em $782 \%$. Quanto ao sentimento geral expresso no Twitter e Facebook, 42\% eram de críticas à conduta do jogador. A crise teve vários desdobramentos, especialmente a partir de um vídeo gravado pelo próprio atleta, orientado por familiares e amigos, no qual expunha imagens da denunciante. Essa ação rendeu um novo agravante contra o jogador, que violou a legislação brasileira que criminaliza a divulgação de cenas de nudez, sexo ou pornografia sem o consentimento da pessoa. À época, o atleta perdeu contratos de publicidade e teve os seus índices de audiência nas mídias sociais prejudicado.

Crises são iminentes, seja no âmbito organizacional ou de pessoas físicas. Não se escolhe passar por uma crise. Porém, é possível escolher como passar por ela. Dornelles (2012) alerta para algumas caraterísticas que vem 
pautando o comportamento de muitas organizações no enfrentamento às crises, entre as quais: tratá-las como elemento surpresa, falta de hábito para lidar com a mídia e perda de controle do fluxo de informações. São posturas que não condizem com o cenário atual e podem parecer um tanto ingênuas, ou mesmo pouco éticas.

Há que se ter presente a necessidade de discutir abertamente o tema, envolver todos os atores organizacionais, educá-los para situações de instabilidade e perda de controle. Para além de construir um plano de prevenção e gestão de crises, garantir que as pessoas estarão minimamente preparadas para se posicionarem em momentos de incerteza, de que a organização dispõe de estruturas e recursos para enfrentar os problemas. No pós-crise, gerar aprendizados que contribuam para um sistema organização-públicos mais eficiente, maduro e preparado para novos imprevistos.

\section{APRENDIZADOS QUE GERAM SISTEMAS MAIS EFICIENTES}

Partindo-se de uma perspectiva mais ampla, pode-se dizer que uma sociedade dispõe de todas as condições necessárias para aprender com os seus erros e, a partir disso, construir sistemas e relacionamentos mais eficientes e duradouros. Nessa direção, a geógrafa francesa Veyret (2015) propõe que grandes crises e catástrofes podem ensinar comunidades a melhorarem o seu arranjo social através do acúmulo de experiência e conhecimento. Cita casos de países europeus que passaram por crises envolvendo incêndios e terremotos e, a partir desse cenário, reorganizaram condições arquitetônicas e urbanísticas, entendendo riscos e crises como elementos integrados. Por outro lado, alerta que esse aprendizado depende da vontade das pessoas, precisa ser incentivado e construído de forma intencional. "As crises e as catástrofes frequentemente fornecem a ocasião para um novo arranjo urbano, para um novo uso que integra melhor o risco, mas isso está longe de ser sempre o caso" (VEYRET, 2015, p.48). Exemplos que ilustram essa não produção de aprendizados com catástrofes no Brasil são recorrentes.

A crise envolvendo o rompimento da barragem de rejeitos de minério da empresa Samarco Mineração S.A. (empreendimento conjunto da brasileira Vale S.A. e da anglo-australiana BHP Billiton), na cidade de Mariana, Estado de Minas Gerais, no ano de 2015, foi considerado um dos desastres industriais com maior impacto ambiental na história do país, deixando 19 mortos. Todos os impactos e desdobramentos da crise, no entanto, não foram suficientes para a construção de aprendizados que permitissem evitar ou diri- 
mir os efeitos de uma nova crise com impactos ainda maiores. Em janeiro de 2019, na cidade de Brumadinho, Estado de Minas Gerais, o rompimento de outra barragem de rejeitos de minério, de propriedade da Vale S.A. resultou no maior desastre industrial de impacto ambiental e humanitário no Brasil, deixando mais de 250 pessoas mortas, além de vários desaparecidos. Tanto as organizações privadas quanto órgãos públicos envolvidos em ambas as catástrofes, aparentemente, construíram poucos aprendizados entre um e outro acontecimento.

No âmbito organizacional, essa reflexão sobre crises como eventos que podem propiciar aprendizados significativos é trazida pelo relatório do PMI Brightline (2018), anteriormente mencionado. Entre os 1.258 executivos entrevistados, em diversos países, 93\% relataram que suas organizações entraram no "modo crise" durante a crise. Esse "modo crise" é uma expressão utilizada para denominar a realidade operacional acionada por uma organização que passa por uma crise, as mudanças provocadas na forma de se trabalhar e no comportamento dos seus funcionários. Ou seja, a organização aplica o "modo crise" de forma a enfrentar a crise e superá-la. A forma como ela faz isso pode ter grandes impactos nos aprendizados gerados em situações de perda de controle.

Independentemente do tipo de crise pelo qual uma organização passa, o PMI Brightline (2018) sugere que ela pode tirar pelo menos três lições que contribuem positivamente com a estratégia organizacional: repensar as formas tradicionais de trabalho, o modo como as coisas são feitas; provocar mudanças que envolvem pessoas e processos na fase pós-crise; e examinar três áreas chave, quais sejam a priorização de iniciativas estratégicas, a velocidade na tomada de decisões e a melhoria na capacitação de equipes. Crises tem um grande potencial transformador, especialmente se a organização conseguir passar por elas sem que danos mais graves sejam causados.

Acredita-se que essas possíveis lições a serem tiradas de uma situação de crise podem ser parte integrante do plano de prevenção e gerenciamento. Em outras palavras, podem servir como um guia na condução das mudanças necessárias no pós-crise.

Um plano de gestão de crise deve ser simples e flexível, como defende Forni (2017). Entre os seus elementos, destacam-se: 1) escopo estratégico da organização: missão, visão, valores, estruturas e públicos de interesse; 2) riscos inerentes à atuação da organização e formas de gestão na perspectiva global e setorial de comunicação; 3) objetivos esperados e metas a 
serem atingidas com o plano de gestão de crise; 4) mapeamento das situações de crise: crises naturais, tecnológicas, saúde e alimentação, confronto, malevolência, distorção de valores, decepção, má administração; 5) estrutura de gestão de crise: gabinete de crise (responsabilidades e atribuições), recursos financeiros, materiais e humanos da equipe de gestão de crise, porta-voz, auditorias de vulnerabilidade; 6 ) protocolos de comunicação: procedimentos de comunicação interna e de comunicação externa a serem adotados em situações de crise. Ou seja, frente às situações de crise mapeadas, como será o fluxo de comunicação com os públicos (cenário interno e cenário externo), como serão informados, quais serão os canais utilizados, que ações de comunicação serão desencadeadas pela área de comunicação, como serão estruturados o manual de crise e as estratégias de disseminação do plano de gestão de crise junto aos níveis estratégico, tático e operacional; 7) avaliação e diagnóstico: fase de retomada, pós-crise.

Especificamente na fase de retomada, do pós-crise, o plano de prevenção e gerenciamento de crise pode prever estratégias que, conduzidas pelo gabinete de crise, podem facilitar a revisão de processos, de condutas pessoais, apontar para necessidades de qualificação e profissionalização em áreas específicas. Nesse caso, também se confere ao gabinete de crise uma responsabilidade que vai além de "apagar incêndios", elevando suas funções de caráter preventivo e educativo. Além disso, é importante que esses aprendizados pós-crise sejam gerados em todas as instâncias da estrutura organizacional, no sentido de comprometer todos os atores com mudanças coletivas.

\section{CONSIDERAÇÕES FINAIS}

Este artigo teve como principal motivação abordar a crise como um evento iminente, de grande potencial transformador. Crises atingem organizações, figuras públicas e celebridades cotidianamente. Por mais bem estruturado e profissional que seja um plano de prevenção e gestão de crise, dificilmente conseguirá prever todos os cenários de crise possíveis em contextos tão mutáveis como os das sociedades capitalistas.

Como primeiro objetivo, definiu-se propor o entendimento de crise como uma das etapas do processo de cooperação-conflito no sistema organização-públicos, a qual precisa ser diferenciada de fatos, insatisfações ou boatos isolados. Nesse tocante, foram trazidas perspectivas teóricas que inserem a crise como um dos níveis possíveis dos estágios cooperação/con- 
flito no sistema organização-públicos. Ancorado na teoria da função organizacional política de relações públicas, o conceito de crise trata da instabilidade e perda de controle da relação entre a organização ou pessoa física e um determinado público.

Num segundo momento, buscou-se contribuir para o entendimento de crises como eventos inevitáveis, os quais possuem tanto um grande poder de impacto negativo sobre a imagem e reputação, quanto uma forte capacidade de gerar aprendizados para todos os atores envolvidos. Sendo assim, foram sugeridas iniciativas que podem ser desenvolvidas nos planos de prevenção e gestão de crise no sentido de conduzir o sistema organização-públicos para o aprendizado coletivo.

Por fim, acredita-se que as pesquisas na área de gestão de crises no Brasil devem evoluir no sentido de capacitar o profissional de relações públicas para atuações mais especializadas nessa área. Além disso, é preciso buscar construir estudos interdisciplinares, envolvendo outras áreas como gestão, estratégia, gestão de riscos, publicidade, jornalismo.

\section{REFERÊNCIAS}

COHEN, Anne. How To Manage A Celebrity Crisis In A Post-Weinstein World. MSN

Entertainment, August, 2019. Disponível em: <https://www.refinery29.com/en-us/2017/12/182774/pr-crisis-celebrity-publicists-hollywood-scandals >. Acesso em: 11 nov. 2019.

DECODE RESEARCH AND ANALYTICS. Caso Neymar no digital. Decode Brasil Fan Page, 2019. Disponível em: <https://www.facebook.com/decode.buzz/posts/698591757240656?comment_id=700622830370882\&comment_tracking=\%7B\%22tn\%22\%3A\%22R\%22\%7D>. Acesso em: 14 nov. 2019, 16:26:32.

DELOITTE. Inteligência em gestão de riscos e antecipação a crises: a estrutura e as práticas de prontidão das organizações. Deloitte Brasil, 2015. Disponível em: $<$ https://www2. deloitte.com/content/dam/Deloitte/br/Documents/risk/Gest\%C3\%A3oRiscos2015.pdf> Acesso em: 11 de nov. de 2019.

DORNELLES, Souvenir Maria G. Planos de Prevenção para Gerenciamento de crises de opinião pública. In: (org.). Relações Públicas: planejamento e comunicação. Porto Alegre, RS: Edipucrs, 2012. cap.5, p.65-81.

FORNI, João José. Gestão de Crises e Comunicação. 2. ed. São Paulo: Atlas, 2017.

GRESSLER, Rodrigo Adonai. Crises no mercado cinematográfico de Hollywood: uma análise do posicionamento de figuras públicas. Porto Alegre: UFRGS, 2018. Originalmente apresentada como monografia de graduação, Universidade Federal do Rio Grande do Sul, 2018. Disponível em: <https://lume.ufrgs.br/handle/10183/193030>. Acesso em: 14 nov. 2019. 
PMI BRIGHTLINE. Project Management Institute Brightline Initiative. Learning from crisis mode: implications for better strategy implementation. PMI: Newton Square, USA, 2018.

SHINYASHIKI, R.T.; FISCHER, R.M.; SHINYASHIKI, G. A importância de um sistema integrado de ações na gestão de crises. Revista Organicom, ano 4, n. 6, $1^{\circ}$ sem. 2007, p. 149159.

SIMÕES, Roberto Porto. Relações públicas: função política. 3. ed. São Paulo: Summus, 1995 .

VEYRET, Yvette (org.). Os riscos: o homem como agressor e vítima do meio ambiente. São Paulo: Contexto, 2015. 


\section{Ana Karin Nunes}

Professora e pesquisadora da Faculdade de Biblioteconomia e Comunicação da UFRGS. Doutora em Educação. Mestre em Comunicação Social. Graduada em Relações Públicas. Responsável pela disciplina de Laboratório de Gestão de Crise e Comunicação de Risco do Curso de Relações Públicas da Fabico.

E-mail: ana.karin@ufrgs.br 